DOI: 10.18027/2224-5057-2017-7-3s1-61-65

Цитирование: Рыков М. Ю. Основные показатели, характеризующие медицинскую помощь детям с онкологическими заболеваниями в Российской Федерации // Злокачественные опухоли. - 2017. - Т. 7. - № 3 , спецвыпуск 1. - С. 61-65.

\title{
Основные показатели, характеризующие медицинскую помощь детям с онкологическими заболеваниями в Российской Федерации
}

\author{
М. Ю. Рыков ${ }^{1,2}$ \\ ' Национальный медицинский исследовательский центр онкологии им. Н. Н. Блохина Минздрава России, Москва, Российская Федерация \\ ${ }^{2}$ Первый Московский государственный медицинский университет им. И. М. Сеченова Минздрава России, Москва, Российская Федерация
}

\section{Резюме:}

Введение. Планирование организации медицинской помощи детям с онкологическими заболеваниями основывается в числе прочего на эпидемиологических данных - заболеваемости и смертности детского населения от злокачественных новообразований.

Материалы и методы. Проанализированы оперативные отчеты органов исполнительной власти в сфере здравоохранения субъектов Российской Федерации, содержащие сведения по заболеваемости, смертности, одногодичной летальности и сроках оказания медицинской помощи детям с онкологическими заболеваниями в субъектах.

Результаты. В 2016 г. в Российской Федерации выявлено 3785 детей с онкологическими заболеваниями, из них активно 265 (7\%). Количество умерших детей с онкологическими заболеваниями составило 779, из них 265 - из числа выявленных в 2016 г. Заболеваемость составила 13 на 100 тыс. детского населения в возрасте 0-17 лет, смертность - 2,7, одногодичная летальность - 7\%. Среднее время, затраченное на установление диагноза, включая гистологическую верификацию, составило 14 дней, для пациентов, умерших в 2016 г., - 27,2 дня. Среднее время, прошедшее от момента верификации диагноза до начала лечения, составило 6 дней, для умерших в 2016 г. пациентов - 4,8 дня.

Заключение. Отмеченная динамика свидетельствует о повышении онкологических заболеваний у детей, а следовательно, о совершенствовании методов диагностики. Учитывая, что среднемировые значения заболеваемости составляют 15 на 100 тыс. детского населения, можно прогнозировать дальнейший рост заболеваемости (выявляемости) до 4500 первичных пациентов к 2022 г. Таким образом, в настоящее время ежегодный недоучет составляет порядка 700 (16\%) пациентов. Низкий процент детей, выявленных активно, свидетельствует о не достаточной подготовке врачей первичного звена (участковых педиатров) в плане детской онкологии. Выявлены существенные расхождения статистических данных, представленных в оперативных отчетах, при сравнении с данными Федеральной службы государственной статистики.

Ключевые слова: детская онкология, эпидемиология, злокачественные новообразования, заболеваемость, одногодичная летальность

\section{Информация об авторах:}

Максим Ю. Рыков , к. м. н., старший научный сотрудник отделения опухолей головы и шеи НИИ ДОГ ФГБУ «НМИЦ онкологии им. Н.Н. Блохина» Минздрава России, доцент кафедры онкологии лечебного факультета ФГАОУ ВО «Первый МГМУ им. И. М. Сеченова» Минздрава России (Сеченовский Университет), e-mail: wordex2006@rambler.ru, ORCID: http://orcid.org/0000-0002-8398-7001

\section{Обоснование}

Злокачественные новообразования (3НО), несмотря на достаточную редкость случаев их возникновения, занимают в структуре смертности детей одно из ведущих мест, поднявшись с седьмого места в 2014 г. до пятого в 20152016 гг. [1]. Планирование организации медицинской помощи детям с онкологическими заболеваниями основывается в числе прочего на эпидемиологических данных заболеваемости и смертности детского населения от $3 \mathrm{HO}$. 


\section{Методы}

Проанализированы оперативные отчеты региональных органов исполнительной власти в сфере здравоохранения, содержащие сведения по заболеваемости, смертности, одногодичной летальности и срокам оказания медицинской помощи детям с онкологическими заболеваниями в субъектах Российской Федерации.

\section{Результаты}

В 2016 г. в Российской Федерации выявлено 3785 детей с онкологическими заболеваниями, из них 265 (7\%)активно. Количество умерших детей с онкологическими заболеваниями составило 779, из них 265 - из числа выявленных в 2016 г. Таким образом, одногодичная летальность составила 7\%. На основании численности детского населения рассчитаны следующие показатели: заболеваемость - 13 (здесь и далее - на 100 тыс. детского населения 0-17 лет), смертность - 2,7 (табл.).

Среднее время, затраченное на установление диагноза, включая гистологическую верификацию, составило 14 дней (минимально - 2 дня, максимально - 60 дней), для пациентов, умерших в 2016 г., - 27,2 дня (минимально - 1 день, максимально - 135 дней). Среднее время, прошедшее от момента верификации диагноза до начала лечения, - 6 дней (минимально - 1 день, максимально 21 день), для умерших в 2016 г. пациентов - 4,8 дня (минимально - 1 день, максимально - 17 дней).

В Центральном федеральном округе заболеваемость составила 13,9, активно выявлены 9,1\% пациентов, смертность - 3,6, одногодичная летальность - 7,7\%; среднее время, затраченное на установление диагноза, включая морфологическую верификацию, - 13,6 дней, для умерших пациентов - 9,6 дня; среднее время, прошедшее от момента верификации диагноза до начала лечения 6,2 дня, для умерших пациентов - 4 дня.

В Северо-Западном федеральном округе заболеваемость составила 16,1, активно выявлено 5\% пациентов, смертность $-2,1$, одногодичная летальность $-4 \%$; среднее время, затраченное на установление диагноза, включая морфологическую верификацию, - 14,1 дня, для умерших пациентов - 8,7 дней; среднее время, прошедшее от момента верификации диагноза до начала лечения, - 5,1 дня, для умерших пациентов - 5 дней.

В Южном федеральном округе заболеваемость составила 11,5, активно выявлено 29,7\% пациентов, смертность - 1,8, одногодичная летальность - 6,9\%; среднее время, затраченное на установление диагноза, включая морфологическую верификацию, - 10,7 дней, для умерших пациентов - 96,6 дня; среднее время, прошедшее от момента верификации диагноза до начала лечения, 8,1 дня, для умерших пациентов - 7,2 дня.

Таблица. Основные показатели, характеризующие медицинскую помощь детям с онкологическими заболеваниями в субъектах Российской Федерации (по данным оперативных отчетов органов исполнительной власти в сфере здравоохранения)

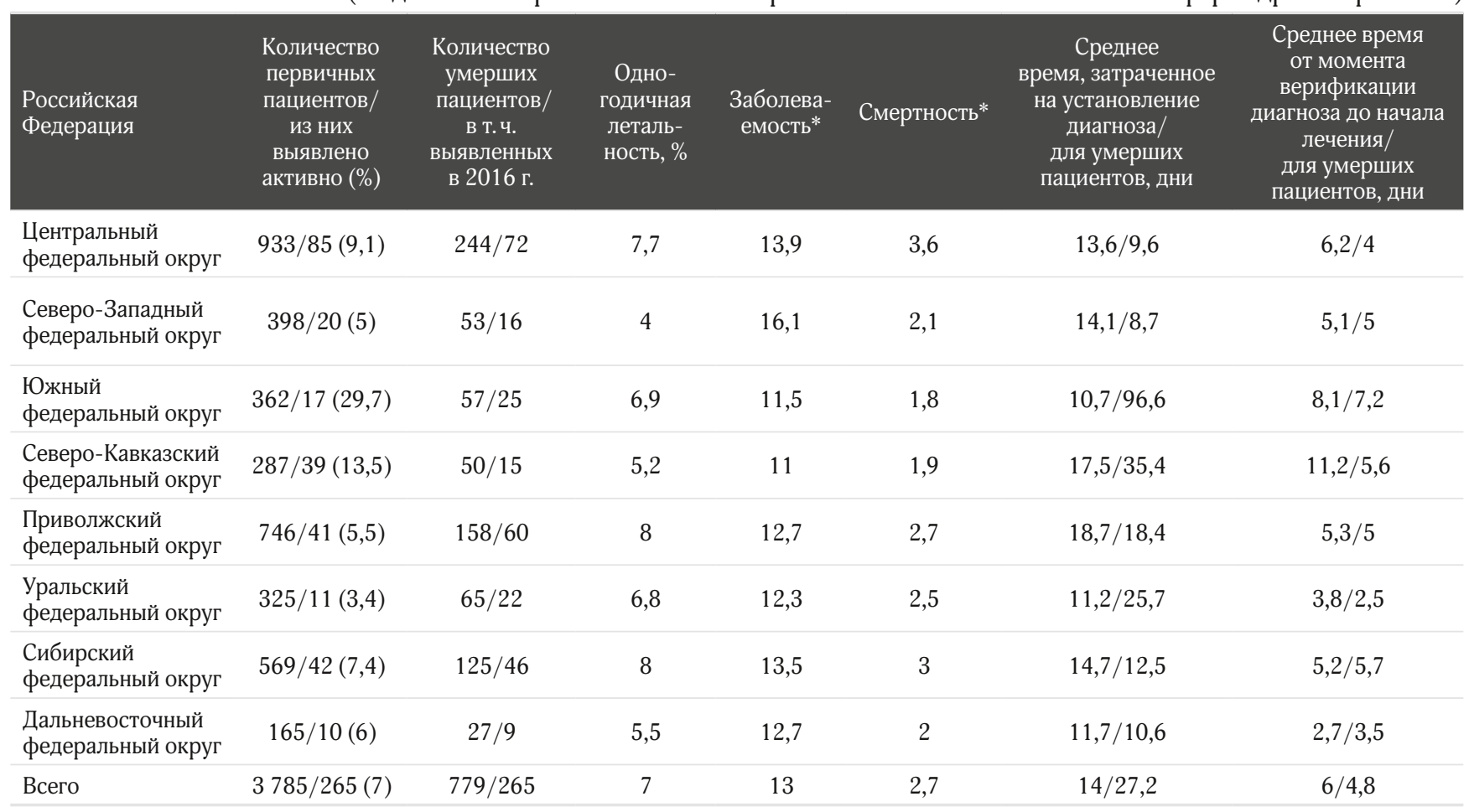

Примечание. * - на 100 тыс. населения в возрасте 0-17 лет, н/д - нет данных. 
В Северо-Кавказском федеральном округе заболеваемость составила 11, активно выявлено 13,5\% пациентов, смертность - 1,9, одногодичная летальность - 5,2\%; среднее время, затраченное на установление диагноза, включая морфологическую верификацию, $-17,5$ дней, для умерших пациентов - 35,4 дня; среднее время, прошедшее от момента верификации диагноза до начала лечения, $-11,2$ дня, для умерших пациентов - 5,6 дня.

В Приволжском федеральном округе заболеваемость составила 12,7, активно выявлено 5,5\% пациентов, смертность - 2,7, одногодичная летальность - $8 \%$; среднее время, затраченное на установление диагноза, включая морфологическую верификацию, - 18,7 дней, для умерших пациентов - 18,4 дня; среднее время, прошедшее от момента верификации диагноза до начала лечения, $-5,3$ дня, для умерших пациентов - 5 дней.

В Уральском федеральном округе заболеваемость составила 12,3, активно выявлено 3,4\% пациентов, смертность - 2,5, одногодичная летальность $-6,8 \%$; среднее время, затраченное на установление диагноза, включая морфологическую верификацию, - 11,2 дня, для умерших пациентов $-25,7$ дней; среднее время, прошедшее от момента верификации диагноза до начала лечения, - 3,8 дня, для умерших пациентов - 2,5 дня.

В Сибирском федеральном округе заболеваемость составила 13,5, активно выявлено 7,4\% пациентов, смертность - 3, одногодичная летальность - 8\%; среднее время, затраченное на установление диагноза, включая морфологическую верификацию, - 14,7 дней, для умерших пациентов - 12,5 дня; среднее время, прошедшее от момента верификации диагноза до начала лечения, $-5,2$ дня, для умерших пациентов - 5,7 дней.

В Дальневосточном федеральном округе заболеваемость составила 12,7, активно выявлено 6\% пациентов, смертность - 2, одногодичная летальность - 5,5\%; среднее время, затраченное на установление диагноза, включая морфологическую верификацию, - 11,7 дней, для умерших пациентов - 10,6 дня; среднее время, прошедшее от момента верификации диагноза до начала лечения, - 2,7 дней, для умерших пациентов - 3,5 дня.

Таким образом, наибольшая заболеваемость зарегистрирована в Северо-Западном федеральном округе $(16,1)$, наименьшая - в Северо-Кавказском (11). Наибольшие показатели смертности отмечены в Центральном федеральном округе $(3,6)$, наименьшие - в Южном федеральном округе $(1,8)$.

Наиболее высокий процент пациентов, выявленных активно, зарегистрирован в Южном федеральном округе $(29,7)$, наиболее низкий - в Уральском федеральном округе $(3,4)$.

Наиболее низкая одногодичная летальность отмечена в Северо-Западном федеральном округе (4\%), наиболее высокая - в Приволжском и Сибирском федеральных округах (8\%).
Наименьшее среднее время, затраченное на установление диагноза, включая морфологическую верификацию, зарегистрировано в Южном федеральном округе 10,7 дней, наибольшее - в Приволжском федеральном округе - 18,7 дней. Для умерших в 2016 г. данные показатели составили 8,7 (Северо-Западный федеральный округ) и 96,6 дня (Южный федеральный округ).

Наименьшее среднее время, прошедшее от момента верификации диагноза до начала лечения, отмечено в Дальневосточном федеральном округе - 2,7 дней, наибольшее - в Северо-Кавказском федеральном округе - 11,2 дня. Для умерших в 2016 г. данные показатели составили 2,5 (Уральский федеральный округ) и 7,2 дня (Южный федеральный округ).

Учитывая вышеизложенное, наиболее высокая заболеваемость отмечена в Севастополе (42,9), наиболее низкая в Республике Крым (6). Наиболее высокий процент пациентов, выявленных активно, зарегистрирован в Камчатском крае (75). В 31 (36,5\%) субъекте Российской Федерации во время плановых профилактических обследований злокачественных новообразований у детей выявлено не было (Владимирская, Воронежская, Костромская, Орловская, Смоленская, Тамбовская, Тверская, Тульская, Вологодская, Новгородская, Псковская, Астраханская, Кировская, Оренбургская, Курганская, Тюменская, Амурская, Магаданская области; Ненецкий автономный округ; Республики Адыгея, Калмыкия, Крым, Чеченская, Мордовская, Чувашская, Алтай; Пермский край, Приморский край, Хабаровский край; Москва, Санкт-Петербург). Наиболее высокие показатели смертности отмечены в Москве $(6,4)$, наиболее низкие в Республике Крым (0,3). Наиболее высокие показатели одногодичной летальности зарегистрированы в Республике Хакасия (45,5\%), наиболее низкие - в Чеченской Республике $(1,2 \%)$. Наибольшее время, затраченное на установление диагноза, включая морфологическую верификацию, отмечено в Республике Башкортостан - 108 дней, наименьшее - в Мурманской области и Приморском крае 2 дня. Для умерших в 2016 г. пациентов данные показатели составили 596 дней (Волгоградская обл.) и 1 день (Белгородская, Липецкая, Пензенская области). Наибольшее время, прошедшее от момента верификации диагноза до начала лечения, зарегистрировано в Чеченской Республике - 30 дней, наименьшее - во Владимирской, Липецкой, Архангельской, Калининградской, Волгоградской, Свердловской, Кемеровской, Магаданской областях, Республиках Марий Эл, Татарстан, Ханты-Мансийском автономном округе - 1 день. Для умерших в 2016 г. пациентов данные показатели составили 21 (Республика Адыгея) и 1 день (Брянская, Владимирская, Калужская, Орловская, Рязанская, Ярославская, Вологодская, Калининградская, Ростовская, Свердловская, Кемеровская области, Ставропольский край, Республики Башкортостан, Марий Эл, Татарстан, Ханты-Мансийский автономный округ, Красноярский край; Республика Саха, Якутия; Санкт-Петербург). 


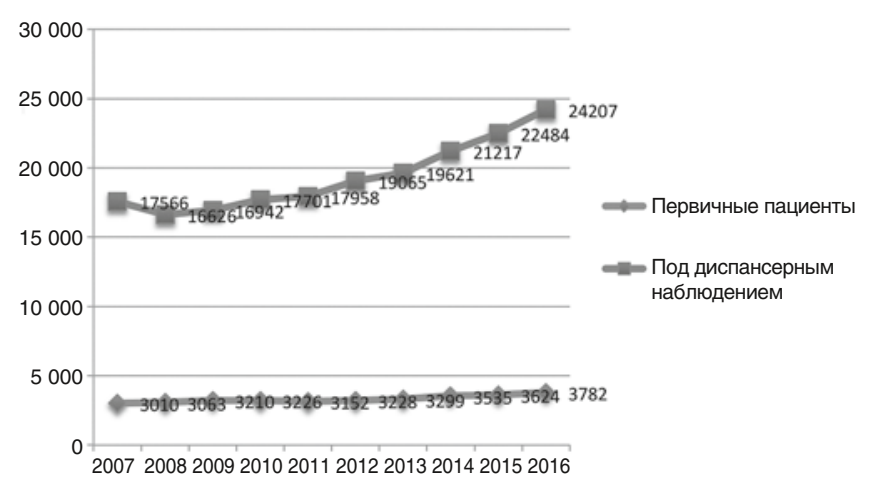

Рисунок 1. Число первичных пациентов и пациентов, находящихся под диспансерным наблюдением (0-17 лет) в 2007-2017 гг.

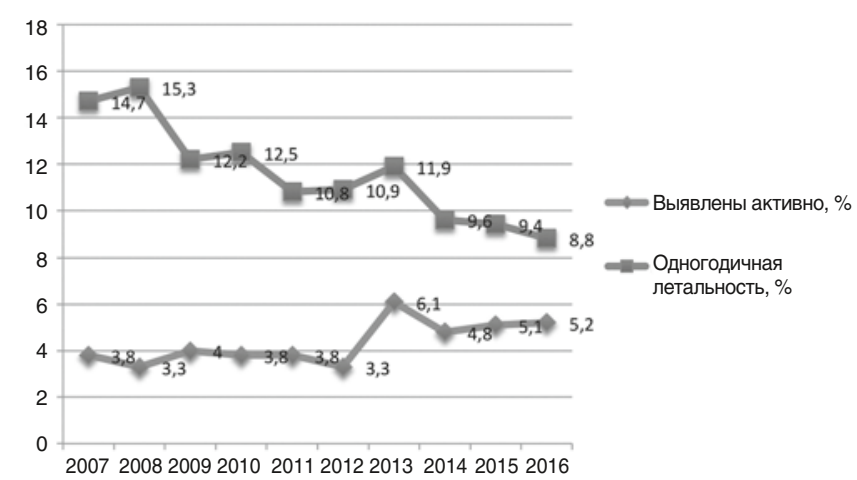

Рисунок 2. Число пациентов, выявленных активно (\%), и одногодичная летальность (\%) в 2007-2016 гг.

\section{Обсуждение}

За последние 10 лет на 25,6\% увеличилось количество первичных пациентов, выявляемых ежегодно (2007 г. - 3 010, 2016 г. - 3 782); количество пациентов, находящихся под диспансерным наблюдением, увеличилось на $37,8 \%$ (2007 г. - 17 566, 2016 г. - 24 207) (рис. 1) [2-7]. Отмеченная динамика свидетельствует о повышении выявляемости онкологических заболеваний у детей, следовательно, о совершенствовании методов диагностики. Учитывая, что среднемировые значения заболеваемости составляют 15 на 100 тыс. детского населения, можно прогнозировать дальнейший рост заболеваемости (выявляемости) до 4500 первичных пациентов к 2022 г. [8]. Таким образом, в настоящее время ежегодный недоучет составляет порядка 700 (16\%) пациентов.

Вместе с тем на 1,4\% увеличилось количество пациентов, выявляемых активно (2007 г. - 3,8\%, 2016 г. - 5,2\%), одногодичная летальность снизилась на 5,9\% (2007 г. $14,7 \%, 2016$ г. - 8,8\%), что свидетельствует о внедрении эффективных протоколов лечения (рис. 2) [1-6].

Низкий процент детей, выявленных активно (во время плановых профилактических осмотров), свидетельствует о недостаточной подготовке врачей первичного звена (участковых педиатров) в плане детской онкологии. Это объясняется в числе прочего, ограниченным количеством пациентов, выявляемых ежегодно, что не позволяет накопить педиатрам достаточно опыта для своевременного выявления 3 НО у детей.

Среднее время, затраченное на установление диагноза, включая гистологическую верификацию, и среднее время, прошедшее от момента верификации диагноза до начала лечения, в настоящее время невозможно сократить, так как оно лимитировано временем проведения методов гистологический верификации диагнозов.

Проанализируем эпидемиологические данные, изложенные в литературных источниках. Согласно сведениям А. Д. Каприна и соавт. [2], в разделе «Показате- ли состояния онкологической помощи детям» указано, что в 2016 г. впервые взяты под диспансерное наблюдение 3782 пациента в возрасте 0-17 лет. Однако в табл. «Сведения о контингенте больных со злокачественными новообразованиями, состоящем на учете в онкологических учреждениях в 2016 г., у детей в возрасте $0-17$ лет» того же сборника приводится другая цифра - 3787 пациентов [2]. Согласно оперативным отчетам 84 органов исполнительной власти в сфере здравоохранения субъектов Российской Федерации ${ }^{1}$ в 2016 г. впервые выявлено 3785 пациентов данной категории (см. табл.). Предположив, что в Карачаево-Черкесской Республике в 2016 г. впервые выявлено 13 пациентов, получаем 3798 пациентов [2].

Также расходится процент пациентов, выявленных активно. Согласно данным указанных выше авторов, в 2016 г. он составил 5,2, тогда как по данным оперативных отчетов -7 .

Различается и количество умерших пациентов. По данным Федеральной службы государственной статистики, в 2016 г. от злокачественных новообразований умерли 1024 ребенка в возрасте 0-17 лет, тогда как по данным оперативных отчетов региональных министерств и департаментов здравоохранения - 779, что свидетельствует об отсутствии достоверных статистических данных по эпидемиологии злокачественных новообразований у детей в Российской Федерации.

В настоящее время учет детей с онкологическими заболеваниями ведется по анатомической локализации опухолей, что недопустимо в детской онкологии, поскольку учет должен основываться на гистологических верификациях диагнозов (нозологических единицах).

Таким образом, в настоящее время в Российской Федерации отсутствуют достоверные статистические данные по эпидемиологии злокачественных новообразований у детей.

\footnotetext{
${ }^{1}$ Министерство здравоохранения Карачаево-Черкесской Республики отчет не предоставило. Дать в скобках - см. выше
} 


\section{Заключение}

Создание базы данных (федерального регистра) детей с онкологическими заболеваниями позволит устранить существующие дефекты статистических данных. Это будет способствовать совершенствованию организации ме- дицинской помощи данной категории пациентов, в том числе позволит оптимизировать маршрутизацию пациентов и расходы бюджетных средств, а также анализировать эффективность лечения и оценивать критерии оценки качества оказания медицинской помощи, что в конечном итоге приведет к повышению выживаемости пациентов.

\section{Литература • References}

1. Эпидемиология злокачественных новообразований у детей: основные показатели в 2011 - 2016 гг./Под. Ред. М. Ю.

Рыкова, В.Г. Полякова. - М.: Изд-во Первого МГМУ им. И. М. Сеченова, 2017. - 208 с. [Epidemiologiya zlokachestvennykh novoobrazovaniy u detey: osnovnye pokazateli v 2011-2016 gg./Pod. Red. M. Yu. Rykova, V. G. Polyakova. - M.: Izd-vo Pervogo MGMU im. I. M. Sechenova, 2017. - 208 s. (In Russ).]

2. Состояние онкологической помощи населению России в 2016 г./Под ред. А. Д. Каприна, В. В. Старинского, Г.В. Петровой. - М.: МНИОИ им. П. А. Герцена - филиал ФГБУ «НМИРЦ» Минздрава России; 2017. - 236 c. [Sostojanie onkologicheskoj pomoshhi naseleniju Rossii v 2016 g./Pod red. AD. Kaprina, VV. Starinskogo, GV. Petrovoj. - M.: MNIOI im. P. A. Gercena - filial FGBU "NMIRC" Minzdrava Rossii; 2017. - 236 s. (In Russ).]

3. Злокачественные новообразования в России в 2015 г. (заболеваемость и смертность)/Под ред. А. Д. Каприна,

В. В. Старинского, Г.В.Петровой. - М.: МНИОИ им. П. А. Герцена - филиал ФГБУ «НМИРЦ» Минздрава России; 2017. [Zlokachestvennye novoobrazovanija v Rossii v 2015 g. (zabolevaemost' i smertnost')/Pod red. AD. Kaprina, VV. Starinskogo, GV. Petrovoj. - M.: MNIOI im. P. A. Gercena - filial FGBU "NMIRC" Minzdrava Rossii; 2017. - 250 s. (In Russ).]

4. Злокачественные новообразования в России в 2014 г. (заболеваемость и смертность)/Под ред. А. Д. Каприна,

В. В. Старинского, Г. В. Петровой. - М.: МНИОИ им. П. А. Герцена - филиал ФГБУ «НМИРЦ» Минздрава России; 2016. - 250 с. [Zlokachestvennye novoobrazovanija v Rossii v 2014 g. (zabolevaemost' i smertnost')/Pod red. AD. Kaprina, VV. Starinskogo, GV. Petrovoj. - M.: MNIOI im. P.A. Gercena - filial FGBU "NMIRC" Minzdrava Rossii; 2016. - 250 s. (In Russ).]

5. Злокачественные новообразования в России в 2013 г. (заболеваемость и смертность)/Под ред. А. Д. Каприна, В.В. Старинского, Г.В.Петровой. - М.: МНИОИ им. П. А. Герцена - филиал ФГБУ «ФМИЦ им. П. А. Герцена» Минздрава России; 2015. - 250 c. [Zlokachestvennye novoobrazovanija v Rossii v 2013 g. (zabolevaemost' i smertnost')/Pod red. A.D. Kaprina, V.V. Starinskogo, G.V. Petrovoj. - M.: MNIOI im. P. A. Gercena - filial FGBU "FMIC im. P. A. Gercena" Minzdrava Rossii; 2015. - 250 S. (In Russ).]

6. Злокачественные новообразования в России в 2012 г. (заболеваемость и смертность)/Под ред. А. Д. Каприна, В.В. Старинского, Г.В. Петровой. - М.: ФГБУ «МНИОИ им. П. А. Герцена» Минздрава России; 2014. - 250 c. [Zlokachestvennye novoobrazovanija v Rossii v 2012 g. (zabolevaemost' i smertnost')/Pod red. A.D. Kaprina, V.V. Starinskogo, G.V. Petrovoj. - M.: FGBU “MNIOI im. P. A. Gercena” Minzdrava Rossii; 2014. - 250 s. (In Russ).]

7. Злокачественные новообразования в России в 2011 г. (заболеваемость и смертность)/Под ред. А. Д. Каприна, В.В. Старинского, Г.В. Петровой. - М.: ФГБУ «МНИОИ им. П. А. Герцена» Минздрава России; 2013. - 289 c. [Zlokachestvennye novoobrazovanija v Rossii v 2011 g. (zabolevaemost' i smertnost')/Pod red. A.D. Kaprina, V.V. Starinskogo, G.V. Petrovoj. - M.: FGBU “MNIOI im. P. A. Gercena" Minzdrava Rossii; 2013. - 289 s. (In Russ).]

8. Долгополов И. С. Верьте только статистике, которую сами правили. Онкопедиатрия. 2016. - T. 3 (2). - C. 88-90. [Dolgopolov IS. Ver'te tol'ko statistike, kotoruju sami pravili. Onkopediatrija. 2016;3 (2):88-90. (In Russ).] D0I: 10.15690/onco. V3i².1542. 